\title{
Enhancement of methane production from barley waste
}

\author{
L. Neves, R. Ribeiro, R. Oliveira, M.M. Alves* \\ Centro de Engenharia Biológica, Universidade do Minho, Braga 4710-057, Portugal
}

Received 22 June 2004; received in revised form 1 December 2005; accepted 1 December 2005

Available online 24 January 2006

\begin{abstract}
Two different approaches were attempted to try and enhance methane production from an industrial waste composed of $100 \%$ barley, which results from production of instant coffee substitutes. In previous work, this waste was co-digested with an excess of activated sludge produced in the wastewater treatment plant located in same industrial unit, resulting in a very poor methane yield $\left(25 \mathrm{LCH}_{4(\mathrm{STP})} /\right.$ $\left.\mathrm{kgVS}_{\text {initial }}\right)$, and low reductions in total solids $(31 \%)$ and in volatile solids $(40 \%)$.

When the barley waste $(\mathrm{BW})$ was subjected to alkaline hydrolysis pre-treatment before co-digestion with activated sludge, the methane production increased to $222 \mathrm{LCH}_{4(\mathrm{STP})} / \mathrm{kgVS}_{\text {initial }}$ and the total and volatile solids reductions increased to $67 \%$ and $84 \%$, respectively.

The second approach, followed in the present work, consisted of co-digestion with kitchen waste $(40 \% \mathrm{BW}, 60 \% \mathrm{kitchen}$ waste). The methane production was $363 \mathrm{LCH}_{4(\mathrm{STP})} / \mathrm{kgVS}_{\text {initial }}$ and the total and volatile solids reductions were $61 \%$ and $67 \%$, respectively.

(C) 2006 Elsevier Ltd. All rights reserved.
\end{abstract}

Keywords: Anaerobic co-digestion; Biogas; Kitchen waste; Alkaline hydrolysis pre-treatment; Barley waste

\section{Introduction}

EU legislation, through the Council Directive 1999/31/ EC [1], states that the amount of biodegradable organic waste that is disposed in landfills should be decreased by $65 \%$, relatively to the total amount of organic fraction of municipal solid waste (OFMSW) produced in 1995, by July 2016. In this framework, anaerobic digestion (biomethanation) can be an alternative potential treatment for biodegradable solid waste.

The anaerobic digestion (AD) process was first employed in the treatment of wastewater. However, in the last two decades, this technology has been started to be used in the management of solid waste. This differs from wastewaters due to its high insoluble organic matter content and chemical oxygen demand (COD). This process is considered as organic recycling as it provides renewable energy (biogas) and organic compost after aerobic stabilisation of the digestate. Nevertheless, some organic solid wastes present a low biodegradability in spite of the high COD

\footnotetext{
*Corresponding author. Tel.: + 351253604402 ; fax: + 351253678986.

E-mail address: Madalena.alves@deb.uminho.pt (M.M. Alves).
}

content and, therefore, studies to enhance the biomethanation process of such wastes are still required.

Coffee waste is a typical example of such a waste. In previous work on the co-digestion of five different wastes from an instant coffee substitutes production industry with sewage sludge, the authors verified that four of the tested wastes gave a methane yield of $240-280 \mathrm{LCH}_{4(\mathrm{STP})} /$ $\mathrm{kgVS}_{\text {initial, }}$, corresponding to $76-89 \%$ of the theoretical methane production. However, a waste composed of $100 \%$ barley, attained only $11 \%$ of the theoretical methane production, which corresponds to a methane yield of $25 \mathrm{LCH}_{4(\mathrm{STP})} / \mathrm{kgVS}_{\text {initial }}$ [2]. This poor methane yield was likely due to the presence of products from the hydrolysis of complex heterocyclic compounds rather than to the levels of volatile fatty acids (VFA), that were lower than in the other tested assays. Moreover, in a study relating the influence of the chemical structure of instant coffee wastes with the anaerobic catabolism, it was found that the individual chemical structure of compounds greatly influences and determines the rate and mechanisms of methanogenic degradation [3].

Acid or alkaline hydrolysis can be applied as a pretreatment to enhance the anaerobic biodegradability of a recalcitrant waste. Alkaline hydrolysis at ambient 
temperatures has been proposed as a chemical pretreatment more compatible with the $\mathrm{AD}$ process, since the bioconversion generally requires an adjustment of $\mathrm{pH}$ by increasing alkalinity [4]. On the other hand, co-digestion with biodegradable wastes has also been successfully and increasingly applied to several agricultural and industrial organic wastes [5].

The aim of this work was to attempt to enhance methane production from a waste composed of $100 \%$ barley by using two different approaches: first, an alkaline pretreatment before co-digestion with sewage sludge, and second co-digestion with kitchen waste, which is the greatest fraction of the OFMSW and is a typical biodegradable waste.

\section{Materials and methods}

\subsection{Analytical methods}

The COD, total solids (TS), volatile solids (VS) and total Kjeldhal nitrogen (TKN) were determined according to standard methods [6]. The methane content of the biogas was measured by gas chromatography using a Porapack Q (180-100 Mesh) column, with $\mathrm{He}$ as the carrier gas at $30 \mathrm{~mL} / \mathrm{min}$ and a thermal conductivity detector. Temperatures of the detector, injector and oven were 110, 110 and $35^{\circ} \mathrm{C}$, respectively. VFA (acetate, propionate, iso-butyrate and $n$-butyrate) were determined by high-performance liquid chromatography using a chrompack column $(300 \times 6.5 \mathrm{~mm})$ and a mobile phase of sulphuric acid $5 \mathrm{mM}$ at $0.7 \mathrm{~mL} / \mathrm{min}$. The column was set at $60^{\circ} \mathrm{C}$ and the detection was made by spectrophotometry at $220 \mathrm{~nm}$.

\subsubsection{Waste characterization}

The barley waste (BW) (100\% barley) was generated from the production of instant coffee substitutes. In this industrial plant there is a wastewater treatment plant to treat domestic and other liquid effluents, producing an excess of activated sludge of about 3.9 tonne/day with a dry matter content of $22 \%$.

The kitchen waste was a blended sample (one week based) from the waste produced in the restaurant of the University of Minho, located in "Campus de Gualtar", Braga, Portugal.

The values of COD, TS, VS, and TKN of the kitchen waste, BW and sewage sludge are given in Table 1.

\subsubsection{Inoculum}

The granular sludge used as inoculum was collected from an upflow anaerobic sludge blanket (UASB) reactor treating a brewery effluent located in Oporto, Portugal. The production of methane due to the residual substrate present in the inoculum was $20 \mathrm{LCH}_{4(\mathrm{STP})} / \mathrm{kgVS}_{\text {sludge. }}$ The quantification of the residual methane production was performed using a pressure transducer technique [7]. The test involves the monitoring of the pressure increase developed in sealed vials without substrate. Strict anaero-
Table 1

Characterization of each type of waste used in terms of COD, TS, VS, TKN

\begin{tabular}{lcll}
\hline Waste \# & Kitchen waste & Barley waste & Sewage sludge \\
\hline COD $(\mathrm{mg} / \mathrm{g})$ & $327 \pm 73$ & $123 \pm 1$ & $6 \pm 1$ \\
TS $(\mathrm{mg} / \mathrm{g})$ & $238 \pm 1$ & $214 \pm 2$ & $7 \pm 1$ \\
VS $(\mathrm{mg} / \mathrm{g})$ & $214 \pm 7$ & $208 \pm 2$ & $6 \pm 1$ \\
TKN $\left(\mathrm{mg} \mathrm{N}-\mathrm{NH}_{4} / \mathrm{g}\right)$ & $13 \pm 1$ & $98 \pm 2$ & $\mathrm{ND}$ \\
\hline
\end{tabular}

ND_not determined.

bic conditions were maintained by using an anaerobic basal medium composed of cysteine-HCL $(0.5 \mathrm{~g} / \mathrm{L}), \mathrm{NaHCO}_{3}$ $(3 \mathrm{~g} / \mathrm{L})$, with the $\mathrm{pH}$ adjusted to 7.0-7.2. Rezasurin was added as an indicator of redox potential. This basal medium was prepared by boiling the medium before adding the bicarbonate. The handheld pressure transducer used was capable of measuring a pressure increase or decrease of two atmospheres $(0- \pm 202.6 \mathrm{kPa})$ over a range of -200 to $+200 \mathrm{mV}$. The sensing element is connected to a digital panel module powered by a $9.0 \mathrm{~V}$ DC transformer. Tests for the quantification of residual methane were performed in $25 \mathrm{~mL}$ vials, in triplicate. The volume of methane produced was corrected to the standard temperature and pressure (STP) conditions.

\subsection{Experimental conditions}

\subsubsection{Alkaline hydrolysis pre-treatment}

For the alkaline hydrolysis pre-treatment the BW was left overnight in a solution of $0.3 \mathrm{~g} \mathrm{NaOH} / \mathrm{gTS}_{\mathrm{BW}}$, at $25^{\circ} \mathrm{C}$. Batch assays of the treated BW were set up keeping the ratio $7 \mathrm{~g} \mathrm{TS}_{\mathrm{BW}} / \mathrm{gTS}_{\text {sludge. This }}$ reflects the relative daily production of $\mathrm{BW}$ and excess of sewage sludge. The $\mathrm{pH}$ was adjusted to 7 and $0.75 \mathrm{~g} \mathrm{NaHCO}_{3} / \mathrm{gTS}_{\text {initial }}$ was added to provide suitable alkalinity. The assays were carried out at $37^{\circ} \mathrm{C}$ under stirring conditions $(150 \mathrm{rpm})$ and the pressure increase was monitored using the pressure transducer device. At regular time intervals, the vials were depressurised and the biogas composition was analysed for $\mathrm{CH}_{4}$ content. The volume of methane produced was corrected to STP conditions. The results from the biomethanation process were expressed in terms of methane yield $\left(\mathrm{LCH}_{4} / \mathrm{kgVS}_{\text {initial }}\right)$ and in terms of $\%$ methanation, which corresponds to the percentage of methane produced relative to the biochemical methane potential $\left(350 \mathrm{LCH}_{4} / \mathrm{kgCOD}_{\text {initial }}\right)$. All the assays were performed in duplicate. These conditions were similar to the ones applied in the first study of co-digestion of the BW with sewage sludge [2].

\subsubsection{Co-digestion of kitchen waste and barley waste}

Batch reactor configuration and operation: The codigestion of BW and kitchen waste was studied in a batch anaerobic digester of $120 \mathrm{~L}$ with a work volume of $80 \mathrm{~L}$. The waste initially loaded was composed of $60 \%$ kitchen 
waste and 40\% BW (digester I). The digester had an internal water jacket to keep the temperature at $37^{\circ} \mathrm{C}$ and was mechanically stirred 3 times a day. For comparative purposes, $100 \%$ kitchen waste was fed in a second digester (digester II), which was run under the same conditions as digester I.

In both digesters the solid content (TS) of the waste was $22 \%$ and $5 \mathrm{~g} \mathrm{NaHCO}_{3} / \mathrm{L}$ were added to provide suitable alkalinity.

Once a week, the content of the reactors was sampled for $\mathrm{pH}$, soluble COD, VFA, TS and VS. The cumulative biogas production and the corresponding methane content were determined.

\section{Results and discussion}

\subsection{Alkaline hydrolysis pre-treatment}

Fig. 1 presents the cumulative methane production obtained in the co-digestion of the pre-treated BW with sewage sludge.

The comparison of the methane production, \% methanation as well as the TS and VS reduction obtained in this assay, with the previously reported assay where the BW was not pre-treated is given in Table 2 .

The alkaline hydrolysis pre-treatment increased the methane production up to $222 \mathrm{LCH}_{4(\mathrm{STP})} / \mathrm{kgVS}_{\text {initial}}$, achieving $100 \%$ of the theoretical methanation. Further-

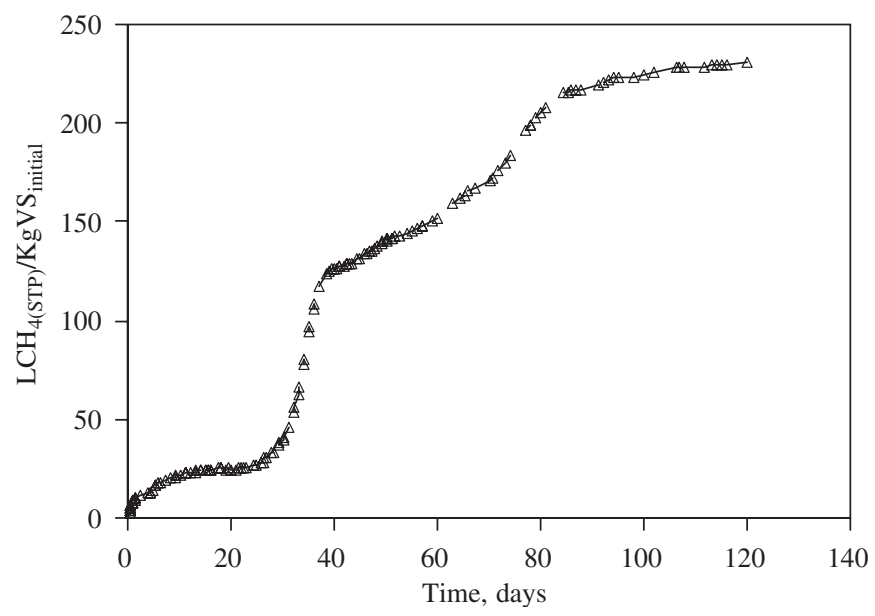

Fig. 1. Cumulative methane production $\left(\mathrm{LCH}_{4}(\mathrm{STP}) / \mathrm{KgVS}_{\text {initial }}\right)$ obtained in the co-digestion of the pre-treated barley waste with sewage sludge. more, this pre-treatment improved the reduction of the TS and VS to $67 \%$ and $84 \%$, respectively.

The pre-treatment of lignocellulosic materials with dilute alkali leads to saponification of esters of uronic acid associated with xylan chains resulting in the breaking of cross-linking [8]. Consequently, there is a marked increase in the swelling capacity and pore size, improving diffusivity of the hydrolytic enzymes and facilitating enzyme-substrate interactions. Hence, acidogenic bacteria can ferment the pre-treated lignocellulose even though no delignification or cellulose hydrolysis occurs during the pre-treatment [8].

The present results show that the alkaline pre-treatment of wastes like barley is beneficial as it significantly improved anaerobic biodegradability. In the assay without pre-treatment reported in the previous work, it was observed that hydrolysis was not the rate limiting step in anaerobic biodegradation of BW [2]. The observed inhibition of methane production was likely caused by the subproducts of the natural hydrolysis process (first step of AD process) that were not suitable for the methanogenic population. The outcome from these two assays elicits the conclusion that the products of the alkaline hydrolysis are less toxic and/or inhibitory for the subsequent stages of the AD process.

\subsection{Co-digestion of kitchen waste and barley waste}

The results obtained for the weekly monitoring of $\mathrm{pH}$, TS, VS and soluble COD are presented in Fig. 2. All the studied parameters presented an identical behaviour in both digesters.

Although the $\mathrm{pH}$ in the co-digestion process (digester I) was slightly higher than in the digester II, at the end of AD process (100 days) the $\mathrm{pH}$ was similar in both digesters. No acidification occurred during the $\mathrm{AD}$ process, which is an indication that the provided alkalinity was suitable.

The evolution of TS (Fig. 2(b)) and VS (Fig. 2(c)) shows that these parameters presented a significant reduction. The profile of soluble COD was different for the two assays. In digester I, soluble COD values were systematically lower than in digester II and attained a residual value of $8 \mathrm{~g} / \mathrm{L}$ around day 100 , whereas in digester II this was only attained by day 172 . This indicates that the codigestion process of $\mathrm{BW}$ and kitchen waste was faster than the single digestion of the kitchen waste. This behaviour can also be observed in the cumulative methane production

Table 2

Methane production, $\%$ methanation, TS and VS reduction in the co-digestion assays with and without pre-treatment

\begin{tabular}{lcccc}
\hline Co-digestion assay \# & Methane production $\left(\mathrm{LCH}_{4(\mathrm{PTN})} / \mathrm{kg} \mathrm{VS}\right.$ initial $)$ & Methanation (\%) & TS reduction (\%) & VS reduction (\%) \\
\hline BW without pre-treatment [2] & 25 & 11 & 31 & 40 \\
BW with pre-treatment & 222 & 100 & 67 & 84 \\
\hline
\end{tabular}

Methane production due to the residual substrate present in the inoculum was discounted. 

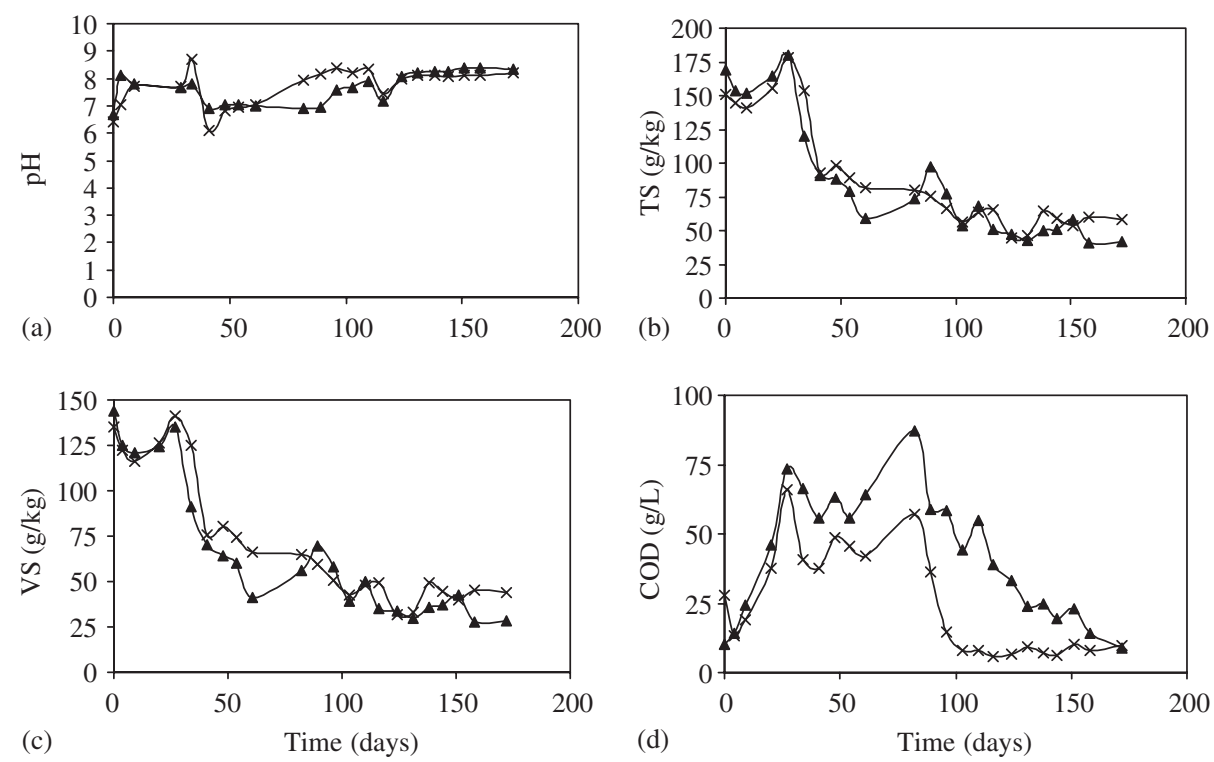

Fig. 2. Time course of the pH (a), TS (b), VS (c) and soluble COD (d) in the anaerobic digester I ( $\times$ ) and II $(\mathbf{\Delta})$.
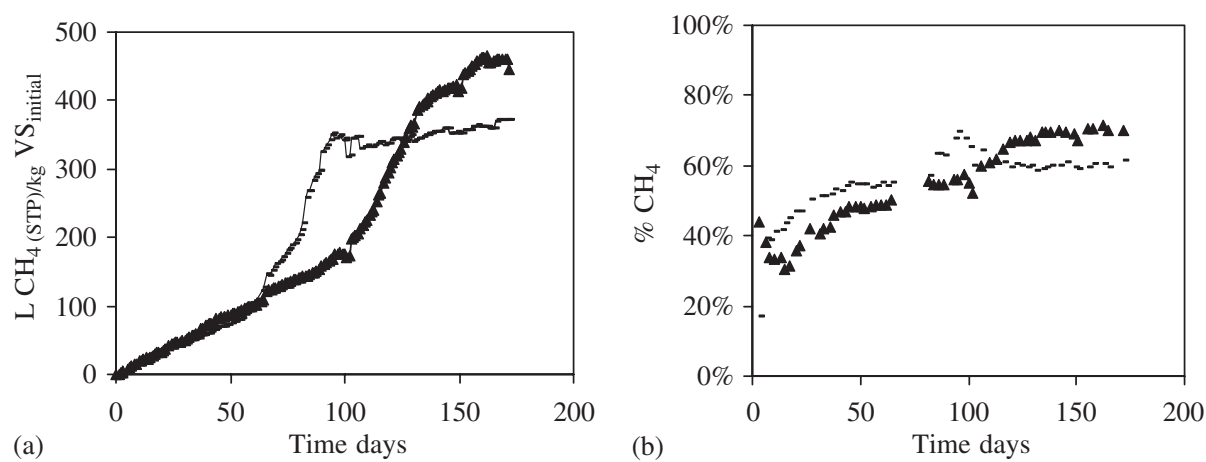

Fig. 3. Cumulative methane production (a) $\left(\mathrm{LCH}_{4}(\mathrm{STP}) / \mathrm{KgVS}_{\text {initial }}\right)$ and methane content (b) $(\%)$ and in the anaerobic digester I (_) and in the anaerobic digester II $(\mathbf{\Delta})$.

curves (Fig. 3a). In this figure the methane content of the biogas produced is also presented (Fig. 3b).

The methane content is somewhat different for the two digesters. In the single digestion of kitchen waste (digester II), the methane content is about $11 \%$ lower than in the codigestion process (digester I), until day 100. However, thereafter, the biogas from the digester II presented a methane content about $15 \%$ higher than the one of the digester I.

Around day 100, the cumulative methane production of the digester I stabilized at the final value that was, at that time, about $99 \%$ higher than that observed in digester II. Nevertheless, at the end, the cumulative methane production was about $20 \%$ higher in digester II compared to digester I.

Methane production, \% of methanation along with the TS and VS reductions for the two digestion processes are presented in Table 3.
The co-digestion of the BW with the kitchen waste was beneficial when compared to co-digestion with sewage sludge. Methane production increased from 25 to $363 \mathrm{LCH}_{4(\mathrm{STP})} / \mathrm{kgVS}_{\text {initial }}$ and the total and volatile solids reductions increased from $31 \%$ to $61 \%$ and from $40 \%$ to $67 \%$, respectively.

Compared with the alkaline pre-treatment, the codigestion with $\mathrm{KW}$ attained more $64 \%$ of methane production. However, the TS and VS reductions were $9 \%$ and $20 \%$ lower, respectively.

From the results of these two approaches, it seems that no inhibition of methanation occurred, as happened when the BW was co-digested with sewage sludge, without pre-treatment. It is feasible to suppose that different intermediates, likely presenting a lower toxicity to the methanogenic populations, were formed in the two approaches studied in the present work. 
Table 3

Methane production, \% methanation, TS and VS reduction in the digester I and II

\begin{tabular}{lllll}
\hline Anaerobic digester \# & Methane production $\left(\mathrm{LCH}_{4(\mathrm{PTN})} / \mathrm{kg} \mathrm{VS}_{\text {initial }}\right)$ & Methanation (\%) & TS reduction (\%) & VS reduction (\%) \\
\hline I & 363 & 92 & 61 & 67 \\
II & 432 & 83 & 75 & 80 \\
\hline
\end{tabular}

Methane production due to the residual substrate present in the inoculum was discounted.

\section{Conclusions}

An alkaline hydrolysis pre-treatment and co-digestion with kitchen waste were beneficial to enhance the methane production of a BW.

Although the best outcome in TS and VS reduction was in the assay with the alkaline hydrolysis, the $\mathrm{pH}$ correction in industrial applications can be a costly process when treating large amounts of waste. The co-digestion of the BW with the OFMSW seems to be attractive from an integrated solid waste management point of view because it only decreases the methane production about $20 \%$, reducing the amount of wastes to be landfilled.

\section{Acknowledgements}

The authors thank to FCT for the financial support given to Lúcia Neves through the project POCTI/1999/ CTA $/ 36524$

\section{References}

[1] Council Directive 1999/31/EC on the landfill of waste, Article 5.

[2] Neves L, Oliveira R, Alves MM. Anaerobic co-digestion of coffee waste and sewage sludge. Waste Management 2006;26(2): $176-81$.

[3] Azhar NG, Stuckey DC. The influence of chemical structure on anaerobic catabolism of refractory compound: a case study of instant coffee wastes. Water Science and Technology 1994;30(12):223-32.

[4] Pavlostathis SG, Gosset JM. Alkaline treatment of wheat straw for increasing anaerobic digestion. Biotechnology and Bioengineering 1985;27:334- 44 .

[5] De Baere L. Anaerobic digestion of solid waste: state of the art. Water Science and Technology 2000;41(3):283-90.

[6] APHA, AWWA, WPCF standard methods for the examination of water and wastewater. 17th ed., Washington, DC, 1989.

[7] Colleran E, Concannon F, Goldem T, Geoghegan F, Crumlish B, Killilea $\mathrm{E}$, et al. Use of methanogenic activity tests to characterize anaerobic sludges, screen for anaerobic biodegradability and determine toxicity thresholds against individual anaerobic trophic groups and species. Water Science and Technology 1992;25:31-40.

[8] Data R. Acidogenic fermentation of corn stover. Biotechnology and Bioengineering 1981;23:61-77. 